\title{
INTELLIGENT CORSETTE FOR TREATMENT OF SCOLIOSIS
}

Péter Tamás, József Molnár, Norbert Szakály

Budapest University of Technology and Economics, Mechanical Engineering Faculty, Department of Mechatronics, Optics and Engineering Informatics

tamas@mogi.bme.bu

Keywords: scoliosis, corsette, force resisting sensor, accelerometer, thermometer, calibration

\section{Introduction}

Spinal disorder (Figure 1.) is dangerous and widespread disease for young girls, nowadays. Spinal disorders may be corrected by gymnastic, corsets and operations. Every case is individual. It is very important that the disorder should be detected as early as possible. ${ }^{1}$ After computer aided diagnostics (CADM Computer Aided Diagnostic in Medicine) if necessary an automatic custommade corset could be realized to make corrections and avoid operations. The primary information for CAD/CAM system is obtained from the special 3D modelling of humans body ${ }^{2}$ and after the measuring the influence of device. We want to reform the shape of corsets, and the efficiency of treatment. Corsets are made in practical way, patients wear them, health staff asks the patients about wearing the corset is comfortable or not, first when making corset, after a periodic wearing time. No exact force and wearing information day-after-day. We created a wearable microcontroller-based measuring system to get and collect information forces between patient and corset, moving and temperature data to determine a wearing time interval.

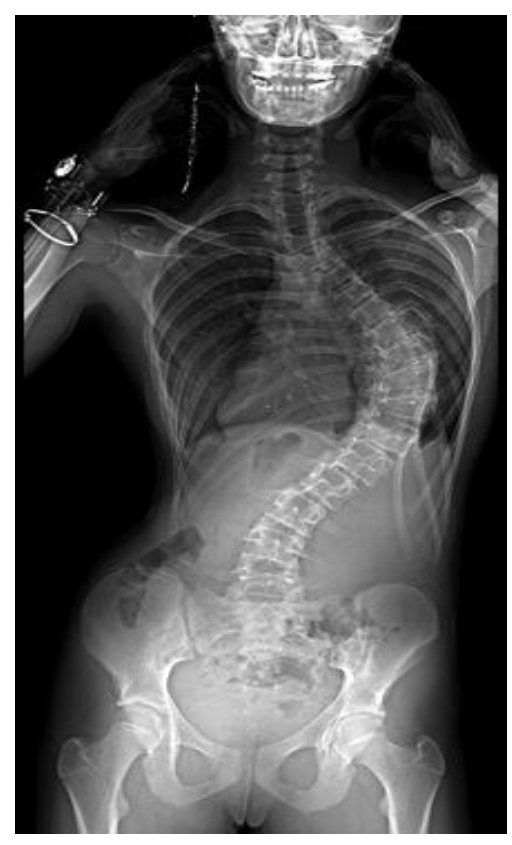

Figure 1. 2D EOS AP spinal rtg. ${ }^{3}$ 


\section{Method, the measuring equipments}

\subsection{Using FSR sensors}

We were looking for a useable sensor between the patient and corset. Main requirements are: lightweight, thin enough, plastic, electrically connectable sensor. We do not want too precise force measurement, because in this application we wanted to create categories on display: "not touching", "too small force", "normal force", "too much force". Nobody wants the exact force measurement or more digits. The metal force sensors found in kitchen or bathroom scales are too big, and hard to fix on the back side of the corset. Interlink Electronics' FSR sensors seemed applicable in corsets (Figure 2.). FSR stand for "Force Sensing Resistor", made from thin polymer film and conductive material. They are changing resistance when applying a force its area, so we can detect a force, and pressure too. FSR sensors are plastic, $0.55 \mathrm{~mm}$ thin, and fixable with adhesive material to a corset. However, because the polymer material's properties, the sensor's resistance is near exponential, and has an elastic, time-dependent change (Figure 3.). These problems can be handling by long-time calibration process.

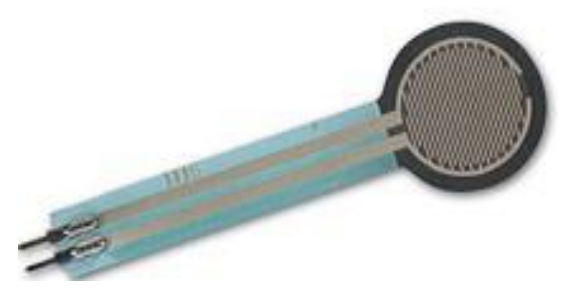

Figure 2. FSR sensor ${ }^{4}$

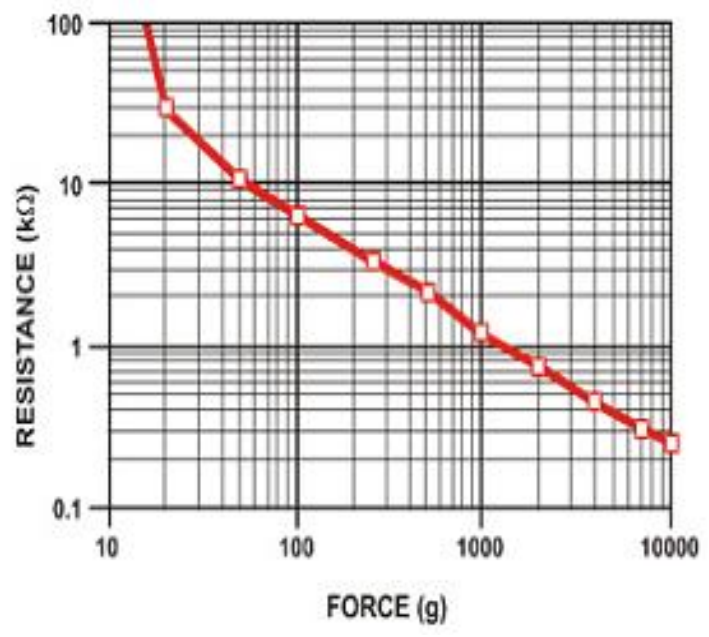

Figure 3. FSR sensor characteristic ${ }^{4}$

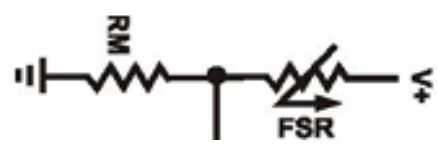

Figure 4. The voltage divider 
We can use an FSR sensor in a simple voltage divider, output voltage equation:

$$
V_{\text {out }}=\frac{R_{M}}{R_{M}+R_{F S R}} \cdot V+
$$

By changing resistor $\mathrm{R}_{\mathrm{M}}$ we can set the output characteristic, and force amplitude. (Figure 5). ${ }^{4}$

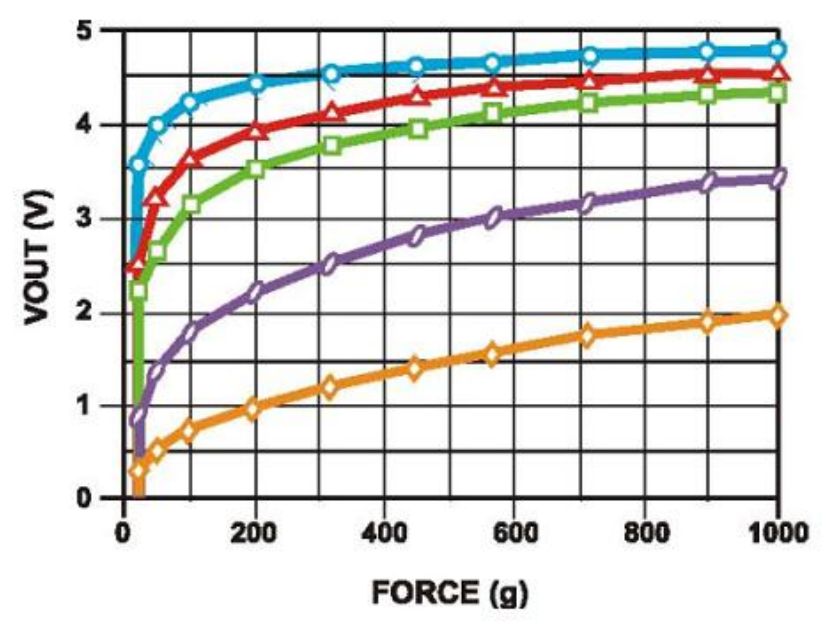

\section{RM VALUES}

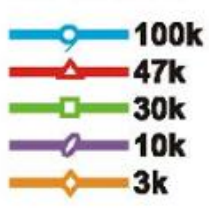

F vs. V for Part No. 402 Interlink Force Tester $1 \mathrm{~cm}^{2}$ circular flat meta actuator

Figure 5. Output characteristic of sensors $\mathrm{v}^{4}$

\subsection{Thermometer specification}

In addition to force sensors, we measure other parameters in a corset: temperature and patient's moving situation. Thermometer is the simplest ic with readable digital output via i2c bus, type is NXP LM78A.

\subsection{Accelerometer specification}

Moving situation measure can be made with accelerometer, or gyroscope. We designed a low-cost 3 axis accelerometer into the hardware. Accelerometer type is Freescale MMA7455, readable via i2c bus.

The equipment is connected to the corsette. The iCorsette manages sensors and stores data. It has its own memory and it works by battery or by USB.

\section{4 iCorset 1.0 - first version to testing subsystems}

The scheme of the equipment is show non Figure 6. Digital parts work on 3.3V and analogue parts on stabilized $5 \mathrm{~V}$. Voltage converters are needed because of switching between the working modes. 


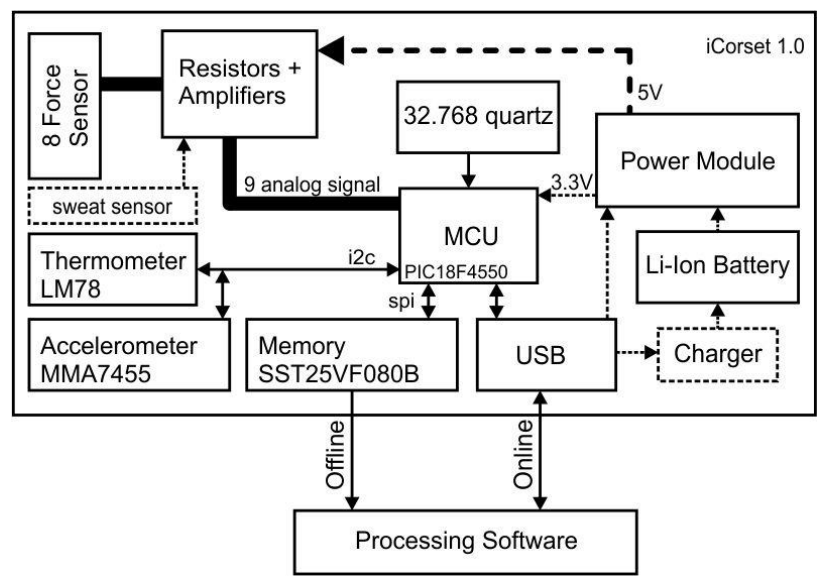

Figure .6 iCorset 1.0 block diagram

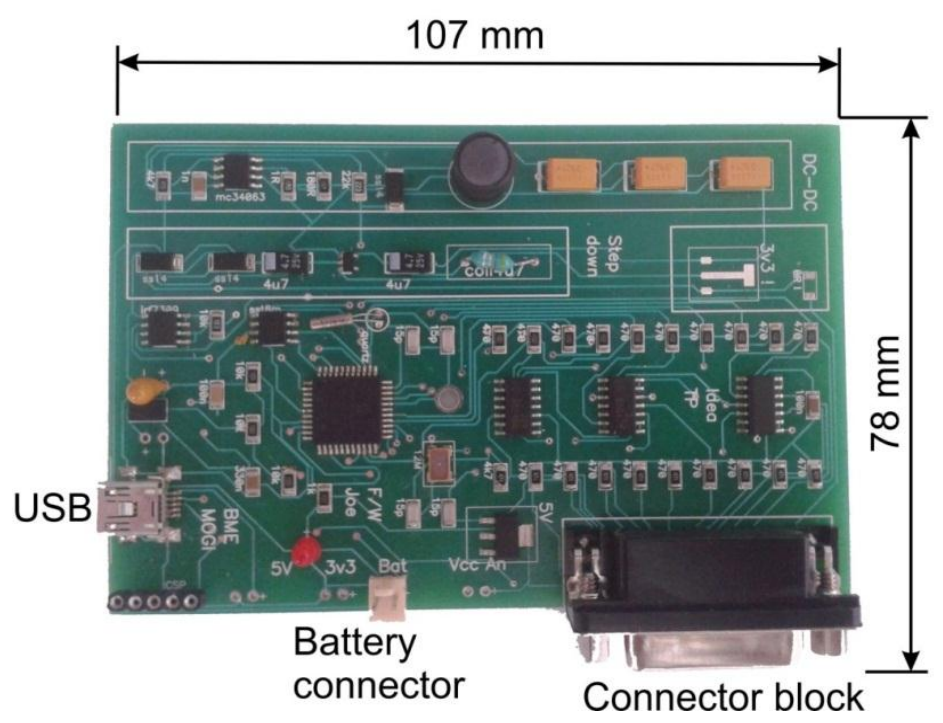

Figure 7 iCorset 1.0

Because this device is battery operated, the analogue part's power supply enabled only the measurement time. FSRs attached to test corset with adhesive, pcb attached with screw M3.

\subsection{Second version based on users opinion: iCorset 2.0}

The first version pcb size was too big: it contains two dc-dc converters, hot-swappable between battery power and USB power, analogue part works from $+5 \mathrm{~V}$ stabilized, digital part works from $+3.3 \mathrm{~V}$ converted supply. The redesigned version works from single $+3.3 \mathrm{~V}$ power supply, stabilized by smd size linear stabilizer, not hot power swappable. Voltage followers were eliminated: sensors connected directly to cpu, creating a small error. New, 2.0 pcb size 40x36 $\mathrm{mm}$, easier to put on the corset's surface. 


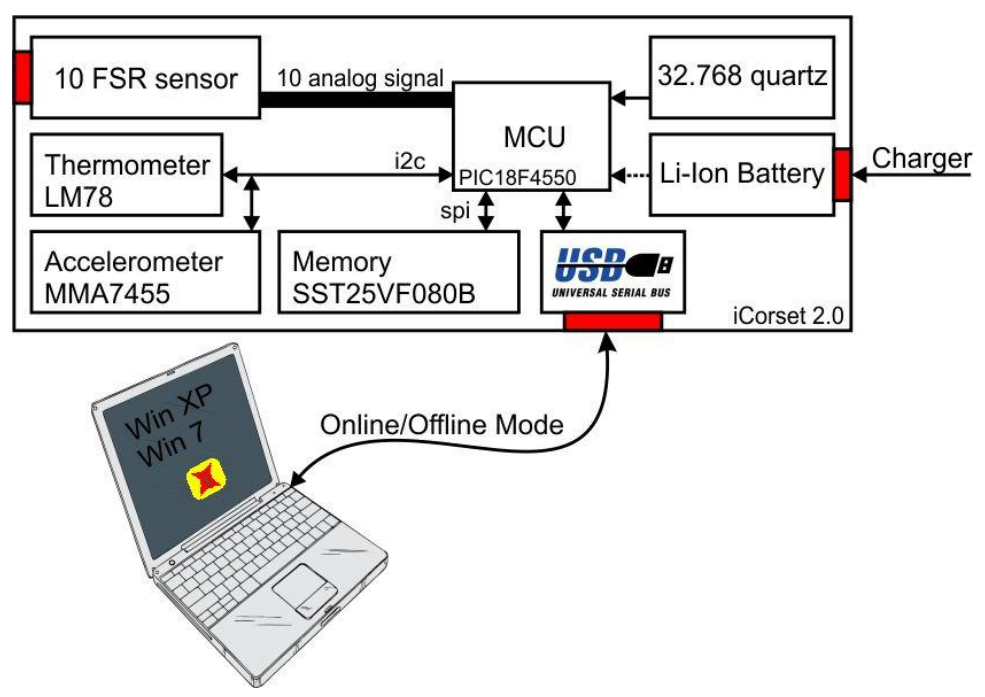

Figure.7. iCorset 2.0 block diagram

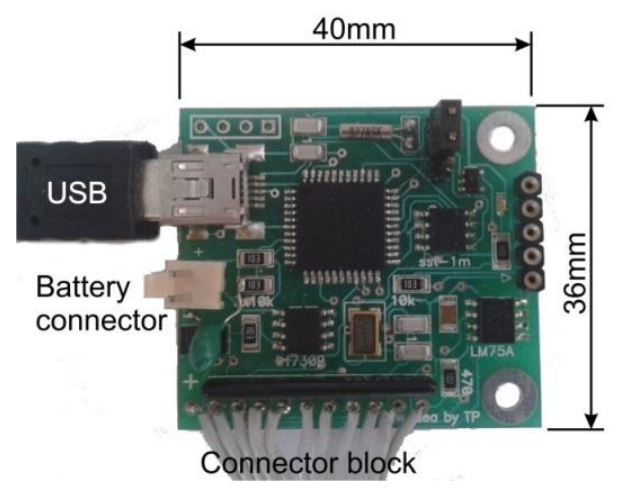

Fig.8. iCorset $2.0 \mathrm{pcb}$

\subsection{Storage capacity of iCorset}

Table 1. shows the data in the memory of the corsette.

\begin{tabular}{|l|l|l|}
\hline Name & Type & Size (byte) \\
\hline Time & Long & 4 \\
\hline Pressure & $10^{*}$ Int & 20 \\
\hline Acceleration & $3^{*}$ Int & 6 \\
\hline Temperature & Int & 2 \\
\hline Summ & & 32 byte/measuring \\
\hline
\end{tabular}

Table 1. Data in iCorset

32 byte memory stores data of one measure. The SST25VF080B EEprom memory has 1Mbyte memory. It is able to store data of 32768 measures. This means more than 22 days capacity if the 
measures follow one after the other in one every minute. It needs to charge the battery in every 2 days. There are nine hours capacity if we make measuring in every second.

\section{Discussion Calibration of FSR sensors}

Measuring interval of selected sensors is $0.1 \mathrm{~N}-100 \mathrm{~N}$ domain. The forces in the corsette are in this interval. Calibration of sensors ${ }^{5}$ was done by a standard range of weights (Figure 9.).

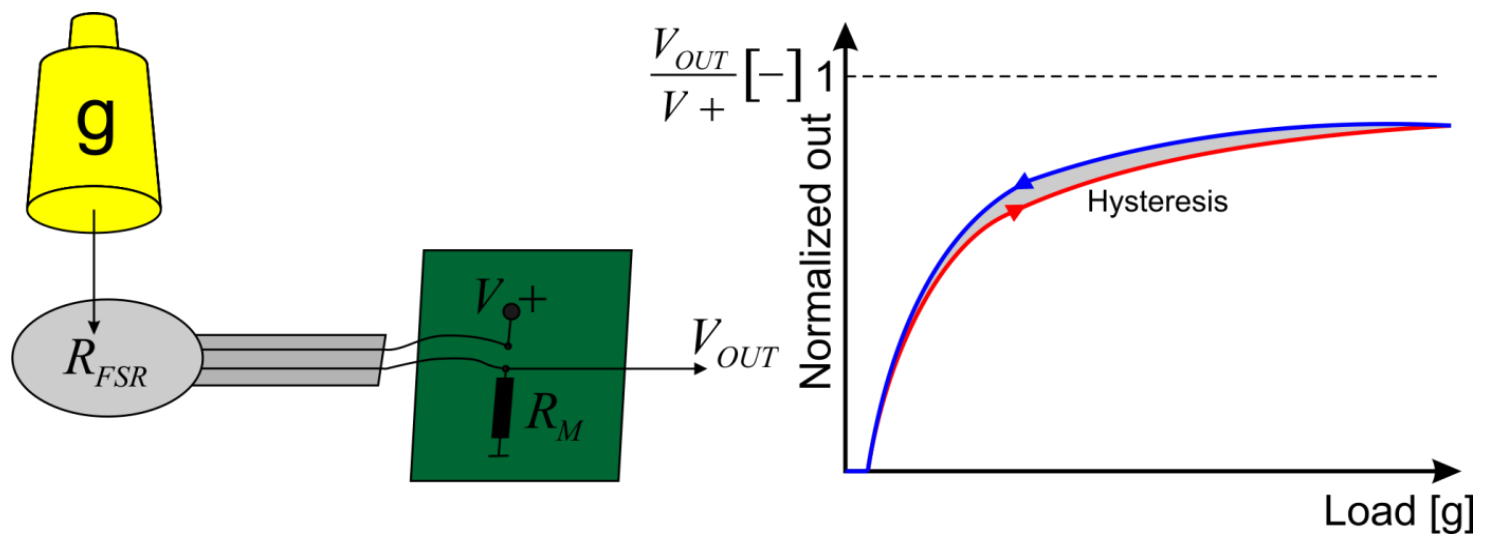

Figure 9. Calibration

There were two problems to solve. ${ }^{6}$ The measured values were functions of time, and there were a hysteresis between the upload and download. Not the output voltage was measure, but the quotient of the output voltage and the input voltage. ${ }^{7}$ In this way the measure is independent from the input voltage. The characteristic is correct even in case of input voltage fluctuation. There is an RM resistance of $470 \mathrm{Ohm}$ (Figure 4.) The measured values are shown in Figure 10. The logarithmic curve follows the measured points well.

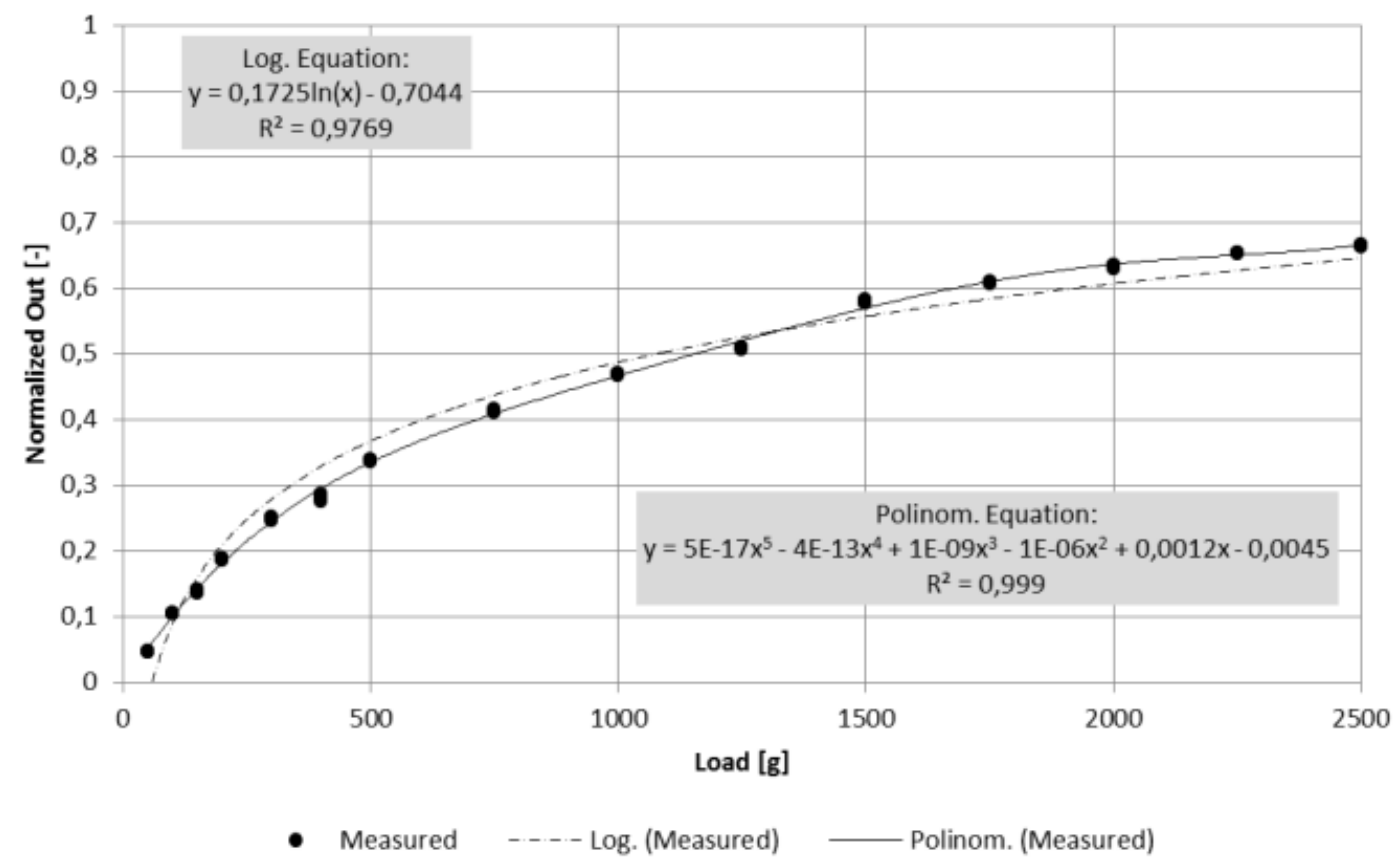

Figure 10. Normalized output as a function of pressure 
Unfortunately if we want exact values than all of the sensor should be calibrated. If we need only approximate value, it is enough to use the normalized values.

\subsection{Software of iCorsette}

There is no display in iCorsette, so we developed a Window application for visualization and processing the data. The Figure 11 shows the actual positions of FSR sensor (left side) and the forces as the function of time.

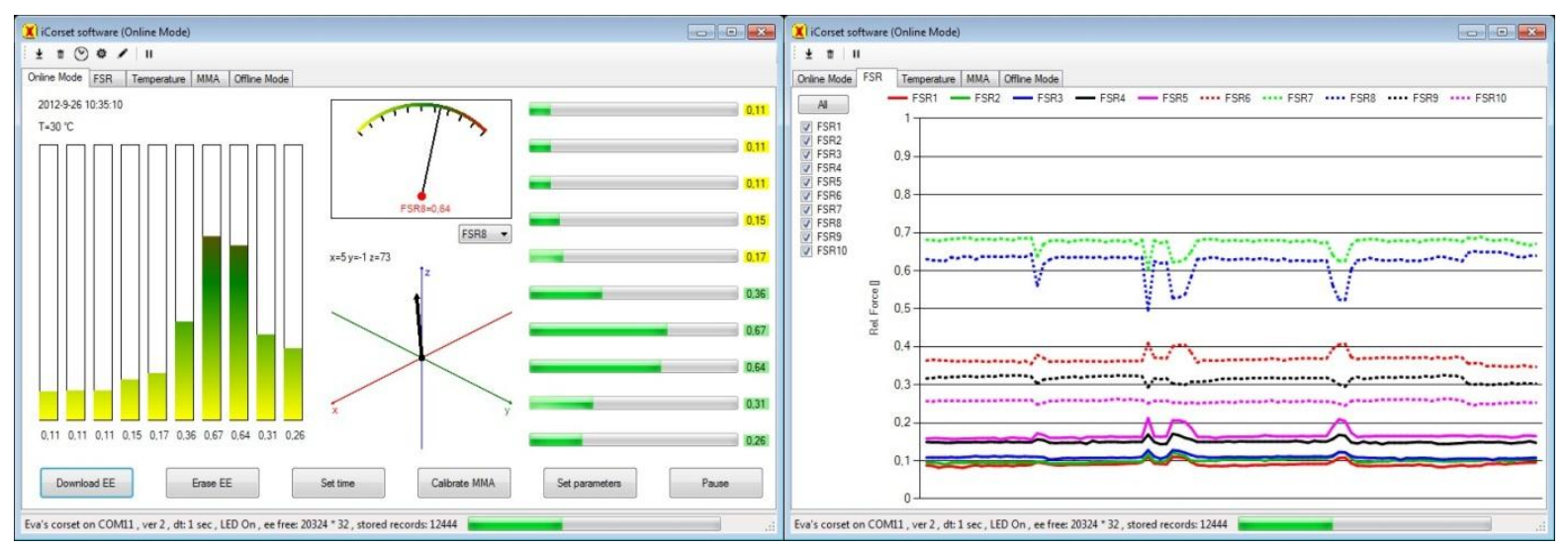

Figure 11. The iCorsette software

ICorsette connected to the computer can solve special tasks. For example it is able to measure of forces along a line. In the left side of Figure 11 we can see the distribution of forces in curve on corsette surface. Acceleration vector is shown too. The downloaded data can be visualized and analyzed (in right side of Figure 11)

\section{Result, test of iCorsette}

The electronics of version I. is connected to the corsette (Figure 12). The iCorsette was tested many times for a week. There were periods of workdays weekend, sport relax and nights also. All activity were traceable on records.

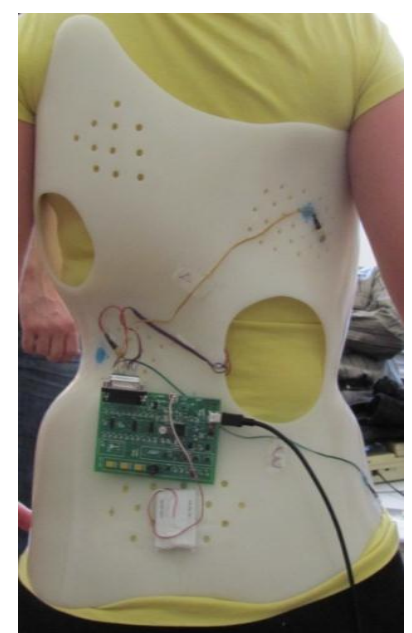

Figure 12. The iCorsette 1.0 
There is the result of a measuring in Figure 13. There are a lot of different periods. The monitored person exersized in the firtst period. Because of leanig on left and right there is high pressure on some sensors (red and green). On the second and forth period the equipment was off. The third and fifth period show normal wearing of corsette.

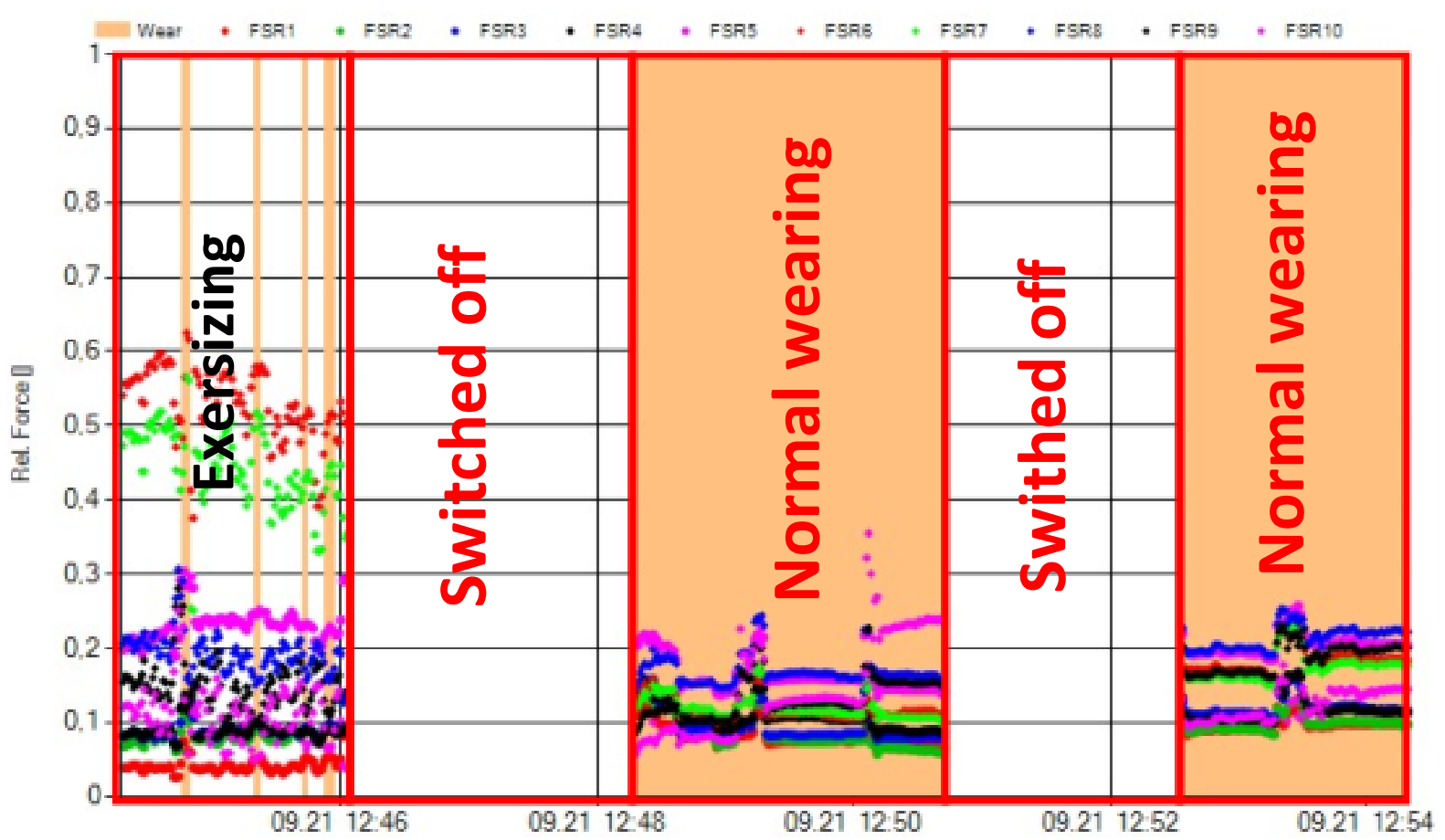

Figure 13. Results of long time measuring

\section{Future work}

After successful testing, some hardware and software modifications can be made. Communication needs to change to wireless, write a mobile phone application, which can send downloaded data over internet to central database.

\section{REFERENCES}

1. Wenzel K, Ábrahám Gy. Measurement of Distortion Using the Moire Method. Experimentelle Technik der Physik 36. 1988.6:429-34.

2. Tamas P, Halasz M, Somló J. 3D Measuring of the Human Body by Robots 5th International Conference Innovation and Modelling of Clothing Engineering Processes - IMCEP 2007, University of Maribor, Faculty of Mechanical Engineering, 2007. October 10-12; Moravske Toplice, Slovenia p 109-115 ISBN 978-961-248-047-9.

3. Martinns PAF, Kwiatkowski L, Franzen V, Tekkaya AE, Kleiner M. Single Point Incremental Forming of Polymers, CIRP Annals - Manufacturing Technology. CIRP 3962009 Articles in Press

4. Interlink Electronics FSR - Force Sensing Resistor Inrtegration Guide and Evaluation Parts Catalog. Version 1.0, Revision D.

5. Flórez JA, Velásquez A. Calibration of Force sensing resistors (fsr) for static and dynamic applications 
6. Hollinger A, Wanderley MM. Evaluation of Commercial Force-Sensing Resistors, NIME06, Paris, France

7. Barnea A, Oprisan C, Olaru D. Force Sensitive Resistors Calibration for the Usage in Gripping Devices, Diagnosis and Prediction in Mechanical Engineering Szstems, DIPRE 12

National Office for Research and Technology (NKTH) of Hungarian Government for their support since this study has been carried out commonly as part of the project GERINCO2 TECH_08-A1/2-2008-0121. 